Keywords: phosphorus, carbon, sulfur, nitrogen, chlorine, fluorine

Retention: permanent

\title{
A REVIEW OF RECENT IMPURITY MEASUREMENTS OF LANL MATERIAL
}

T.B. Edwards

July 2012

Applied Computational Engineering and Statistics Savannah River National Laboratory Aiken, SC 29808

This document was prepared in conjunction with work accomplished under Contract No. DE-AC09-08SR22470 with the U.S. Department of Energy. 
SRNL-STI-2012-00388

Revision 0

\section{DISCLAIMER}

This work was prepared under an agreement with and funded by the U.S. Government. Neither the U.S. Government or its employees, nor any of its contractors, subcontractors or their employees, makes any express or implied: 1. warranty or assumes any legal liability for the accuracy, completeness, or for the use or results of such use of any information, product, or process disclosed; or 2. representation that such use or results of such use would not infringe privately owned rights; or 3. endorsement or recommendation of any specifically identified commercial product, process, or service. Any views and opinions of authors expressed in this work do not necessarily state or reflect those of the United States Government, or its contractors, or subcontractors.

This document was prepared in conjunction with work accomplished under Contract No. DE-AC09-08SR22470 with the U.S. Department of Energy. 
SRNL-STI-2012-00388

Revision 0

\section{REVIEWS AND APPROVALS}

\section{AUTHOR:}

T. B. Edwards, Applied Computational Engineering and Statistics Savannah River National Laboratory

Date

\section{TECHNICAL REVIEWER:}

E. P. Shine, Applied Computational Engineering and Statistics

Date

Savannah River National Laboratory

APPROVER:

P. L. Lee, Manager, Applied Computational Engineering and Statistics

Date

Savannah River National Laboratory 


\section{EXECUTIVE SUMMARY}

The Applied Computational Engineering and Statistics (ACES) group of the Savannah River National Laboratory (SRNL) was asked to review recent measurements performed by the Los Alamos National Laboratory (LANL) on material from that facility that is being considered for processing through the Mixed Oxide (MOX) Fuel Fabrication Facility (MFFF) at the Savannah River Site (SRS). There are specification limits for impurities in the feed to the MOX facility: a maximum limit and an exceptional limit. The limits for an impurity apply to the population of concentration values for that impurity for a class of material that is to be processed through MOX. For the purposes of this report, these limits were defined as follows. The concentration of an elemental impurity, expressed as micrograms of the element per gram of plutonium $(\mu \mathrm{g} / \mathrm{g} \mathrm{Pu})$, is to be no more than the maximum limit for that element for $98 \%$ of the material coming through MOX; that is, $98 \%$ of the material processed at MOX is to have a concentration of the given element less than the maximum limit. In addition, the concentration for a given element is to be no more than the exceptional limit for that element for $99.9 \%$ of the material processed through MOX.

The measurements evaluated as part of this study included LANL blend lots 1 through 29 and cover carbon $(\mathrm{C})$, chlorine $(\mathrm{Cl})$, fluorine $(\mathrm{F})$, nitrogen $(\mathrm{N})$, phosphorous $(\mathrm{P})$, and sulfur $(\mathrm{S})$. Note that all of the measurements for each impurity were below their respective maximum (and obviously, therefore, their exceptional) limits. Thus, there is no immediate concern regarding the LANL material being suitable for processing through MOX. Two approaches were used to investigate the quantiles of the impurity populations. The first approach used was a nonparametric approach. While the results from this approach did not indicate any problems for any of the impurities, there was too little data available to lead to confident statements about satisfying the maximum and exceptional limits. Impurity data from additional random samples of the LANL material would be needed to increase the confidence level associated with the results from a nonparametric approach for investigating the population quantiles of interest.

For S, F, and Cl, only a nonparametric approach was used. A second approach, a parametric approach, was attempted for $\mathrm{C}, \mathrm{P}$, and $\mathrm{N}$. However, the results for the $\mathrm{P}$ and $\mathrm{N}$ measurements indicated that each of their respective populations was not well modeled by a normal or by a lognormal distribution. Thus, the conclusions for the $\mathrm{P}$ and $\mathrm{N}$ populations were those provided by the nonparametric approach. From the parametric approach, the results for $\mathrm{C}$ indicated no issue in the LANL material meeting the maximum limit for this element assuming that the measurements for this element follow a lognormal distribution. 


\section{TABLE OF CONTENTS}

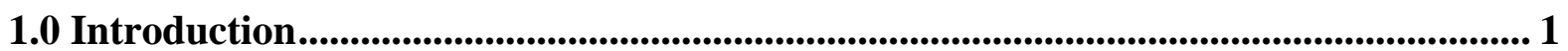

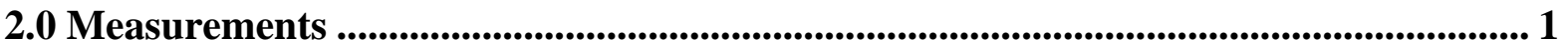

3.0 Confidence Limits for Population Quantiles ....................................................................... 2

3.1 Nonparametric Approach ................................................................................. 3

3.2 Parametric Approach.....................................................................................6 6

3.2.1 Elements with All Measurements above their Detection Limits........................ 7

3.2.2 Elements with Measurements above and below their Detection Limits .......... 10

4.0 Summary and Conclusions ........................................................................................ 12

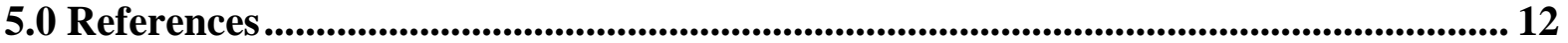


SRNL-STI-2012-00388

Revision 0

This page intentionally left blank. 


\subsection{INTRODUCTION}

The Applied Computational Engineering and Statistics (ACES) group of the Savannah River National Laboratory (SRNL) was asked to review recent measurements performed by the Los Alamos National Laboratory (LANL) on material from that facility that is being considered for processing through the Mixed Oxide (MOX) Fuel Fabrication Facility (MFFF) at the Savannah River Site (SRS). There are specification limits for impurities in the feed to the MOX facility: a maximum limit and an exceptional limit. For the purposes of this report, these limits were defined as follows. The concentration of an elemental impurity, expressed as micrograms of the element per gram of plutonium $(\mu \mathrm{g} / \mathrm{g} \mathrm{Pu})$, is to be no more than the maximum limit for that element for $98 \%$ of the material coming through MOX; that is, $98 \%$ of the material processed at MOX is to have a concentration of the given element less than the maximum limit. In addition, the concentration for a given element is to be no more than the exceptional limit for that element for $99.9 \%$ of the material processed through MOX. For example, the concentration of sulfur (S) must be no more than $250 \mu \mathrm{g}$ $\mathrm{S} / \mathrm{g} \mathrm{Pu}$ for $98 \%$ of the material processed in MOX and no more than $1000 \mu \mathrm{g} \mathrm{S} / \mathrm{g}$ Pu for $99.9 \%$ of the material processed in MOX.

Thus, these specification limits for an elemental impurity represent a pair of select quantiles (i.e., the $98^{\text {th }}$ and $99.9^{\text {th }}$ quantiles) of the population of concentrations for that impurity for a class of material that is being considered for processing through MOX. One such class of material is that from LANL. The objective of this review was to use recent measurements to assess the performance of the LANL material against these limits. Questions of interest in this assessment included:

- Is there an indication of a problem with the LANL material meeting the specification limit for one or more of the elemental impurities being considered?

- Do the available data on the impurities being considered provide a strong case for limiting the need for additional sampling of the LANL material?

The analyses presented in this report were conducted using JMP Version 9.0.0 [1] and ProUCL Version 4.1.01 [2].

\subsection{MEASUREMENTS}

The measurements evaluated as part of this study included LANL blend lots 1 through 29 and cover carbon $(\mathrm{C})$, chlorine $(\mathrm{Cl})$, fluorine $(\mathrm{F})$, nitrogen $(\mathrm{N})$, phosphorous $(\mathrm{P})$, and sulfur $(\mathrm{S})$. The measurements are provided in Table 1. A numerical value in Table 1 that is led by a " $<$ "indicates a value below detection, with the numerical value representing the detection limit. Also provided in Table 1 are the maximum and exceptional limits for each of these elements. Note that all of the measurements for each impurity are below their respective maximum (and obviously, therefore, their exceptional) limits. Thus, there was no immediate concern regarding the LANL material being suitable for processing through MOX. 
SRNL-STI-2012-00388

Revision 0

Table 1. LANL Measurements

\begin{tabular}{|c|c|c|c|c|c|c|}
\hline BLEND LOT & $\mathbf{C}$ & $\mathbf{N}$ & $\mathbf{S}$ & $\mathbf{F}$ & $\mathrm{Cl}$ & $\mathbf{P}$ \\
\hline 1 & 46 & 16 & $<12$ & $<35$ & $<35$ & 71 \\
\hline 2 & 46 & $<11$ & $<12$ & $<34$ & $<34$ & 22 \\
\hline 3 & 35 & $<12$ & $<12$ & $<35$ & $<35$ & 84 \\
\hline 4 & 69 & $<12$ & $<12$ & $<35$ & $<35$ & 68 \\
\hline 5 & 57 & 49 & $<7.6$ & $<23$ & $<23$ & 45 \\
\hline 6 & 61 & 22 & $<7.6$ & $<23$ & $<23$ & 18 \\
\hline 7 & 49 & $<11$ & $<7.6$ & $<23$ & $<23$ & 23 \\
\hline 8 & 76 & $<11$ & $<11$ & $<23$ & $<23$ & 130 \\
\hline 9 & 110 & 25 & $<11$ & $<23$ & $<23$ & 110 \\
\hline 10 & 88 & $<12$ & $<12$ & $<23$ & $<23$ & 130 \\
\hline 11 & 80.2 & 14.9 & $<11$ & $<23$ & $<23$ & 94 \\
\hline 12 & 80.2 & 19.5 & $<11$ & $<23$ & $<23$ & 130 \\
\hline 13 & 69 & $<14$ & $<11$ & $<23$ & $<23$ & 120 \\
\hline 14 & 100 & 17 & $<11$ & $<23$ & $<23$ & 110 \\
\hline 15 & 46 & 16 & $<12$ & $<23$ & $<23$ & 22 \\
\hline 16 & 99 & 36 & $<11$ & $<23$ & $<23$ & 44 \\
\hline 17 & 38 & 43 & $<12$ & $<23$ & 56.4 & 31 \\
\hline 18 & 34 & 43 & $<11$ & $<23$ & $<23$ & 36 \\
\hline 19 & 54 & 15 & $<11$ & $<23$ & $<23$ & 32 \\
\hline 20 & 127 & 30.5 & $<12$ & $<23$ & $<23$ & 44 \\
\hline 21 & 53 & 29 & $<11$ & $<23$ & $<23$ & 37 \\
\hline 22 & 56 & 390 & $<12$ & $<35$ & $<35$ & 53 \\
\hline 23 & 23 & 275 & $<12$ & $<35$ & $<35$ & 31 \\
\hline 24 & 58 & 255 & $<12$ & $<35$ & $<35$ & 23 \\
\hline 25 & 53 & $<34$ & $<11$ & $<34$ & $<34$ & 44 \\
\hline 26 & 100 & $<30$ & $<12$ & $<35$ & $<35$ & 31 \\
\hline 27 & 84 & $<30$ & $<12$ & $<34$ & $<34$ & 21 \\
\hline 28 & 31 & $<35$ & $<12$ & $<35$ & $<35$ & 27 \\
\hline 29 & 180 & $<35$ & $<12$ & $<35$ & $<35$ & 34 \\
\hline Maximum & 500 & 400 & 250 & $\mathrm{NA}^{f}$ & NA & 200 \\
\hline \multirow[t]{2}{*}{ Exceptional } & 1500 & 400 & 1000 & 500 & 500 & 1000 \\
\hline & \multicolumn{6}{|c|}{ all elements expressed as $\mu \mathrm{g} / \mathrm{g} \mathrm{Pu}$} \\
\hline
\end{tabular}

${ }^{f}$ Not Available ---- there is no individual maximum limit for this element.

\subsection{Confidence Limits For Population QUANTILES}

As stated above, the maximum and exceptional limits for an impurity apply to the population of concentration values for that impurity for a class of material that is to be processed through MOX. For this investigation, it was not enough to know about the summary statistics of the population, such as its mean and standard deviation. Here the shape of the distribution of values in the impurity population and specifically the values of the pair of upper quantiles linked to the specification limits were of primary interest. Statistical methods can be used to support this investigation if the impurity data provided in Table 1 are considered as random samples from these impurity populations. Thus, the populations of interest in this study were those for the $\mathrm{C}, \mathrm{P}, \mathrm{N}, \mathrm{Cl}, \mathrm{F}$, and $\mathrm{S}$, and the statistical methods employed had as their objective the estimation of quantiles of these populations which were to be expressed as confidence limits.

Two approaches were used to investigate the quantiles of each impurity population: a nonparametric (or distribution-free) approach and a parametric approach (i.e., an approach that relies on a specified 
probability distribution to represent the population of possible values for the impurity). The goal in each of these investigations was the determination of confidence limits for select quantiles of the population.

\subsection{Nonparametric Approach}

A nonparametric approach was considered first. There were 29 results reported in Table 1 for each of the indicated elemental concentrations. Two mathematically-equivalent nonparametric methods were applied to each of these sets of measurements. The first utilized an approach presented in [3] that is based on the use of order statistics for the set of measurements from Table 1. These order statistics may be denoted as $X_{(1)}, X_{(2)}, \quad, X_{(29)}$, where $X_{(1)}$ is the smallest measurement and $X_{(29)}$ is the largest measurement in the set of data. Then, a $(1-\alpha) \times 100 \%$ upper confidence limit for the $q^{\text {th }}$ quantile, $Y_{\mathrm{q}}$, of the impurity population $\mathrm{Y}$ may be constructed using the binominal probability distribution by determining the smallest value for $\alpha$ between 0 and 1 such that:

$$
\text { Probability }\left[\mathrm{Y}_{\mathrm{q}}>\mathrm{X}_{(29)} \mid \mathrm{X}_{(29)}\right] \leq \mathrm{q}^{29} \leq \alpha
$$

This approach was used to bound various quantiles of the impurity population represented by any of these random samples with the designated confidence. To restate the conclusion provided by this method, there is at least $(1-\alpha) \times 100 \%$ confidence that at least $\mathrm{q} \times 100 \%$ of the population is less than the largest value seen in the random sample (or largest detection limit if all values are below detection). Table 2 presents a listing of the confidence limits that may be assumed for various quantiles of a population of values that are bounded by the largest value in a random sample of 29 observations. For example, consider the shaded row above in Table 2 . There is $100 \% \times(1-.4)=60 \%$ confidence that $96.89 \%$ of the population is less than the largest value recorded in the set of 29 measurements randomly selected from the population. The last entry presented in Table 2 provides a confidence statement about the largest sample measurement providing an estimate of the $98^{\text {th }}$ percentile of the population. From this entry, there is only $44 \%$ confidence that the largest sample measurement bounds $98 \%$ of the population values. Thus, utilizing this nonparametric approach with the limited amount of data (only 29 measurements for each impurity) available for this investigation did not lead to useful confidence statements about the quantiles of interest. 
Table 2. Confidence Limits for Quantiles using a Nonparametric Approach

\begin{tabular}{|c|c|c|c|}
\hline $\begin{array}{c}\mathbf{n} \\
\text { (sample size) }\end{array}$ & \begin{tabular}{|c|}
$\alpha$ (there is probability of at least $1-\alpha$ \\
that at least $q$ of the population is less than $X_{(29)}$
\end{tabular} & $\begin{array}{c}\text { Confidence } \\
(1-\alpha)\end{array}$ & q (the proportion of the population) \\
\hline 29 & 0.01 & $99 \%$ & 0.8532 \\
\hline 29 & 0.02 & $98 \%$ & 0.8738 \\
\hline 29 & 0.03 & $97 \%$ & 0.8861 \\
\hline 29 & 0.04 & $96 \%$ & 0.8949 \\
\hline 29 & 0.05 & $95 \%$ & 0.9019 \\
\hline 29 & 0.06 & $94 \%$ & 0.9075 \\
\hline 29 & 0.07 & $93 \%$ & 0.9124 \\
\hline 29 & 0.08 & $92 \%$ & 0.9166 \\
\hline 29 & 0.09 & $91 \%$ & 0.9203 \\
\hline 29 & 0.10 & $90 \%$ & 0.9237 \\
\hline 29 & 0.11 & $89 \%$ & 0.9267 \\
\hline 29 & 0.12 & $88 \%$ & 0.9295 \\
\hline 29 & 0.13 & $87 \%$ & 0.9321 \\
\hline 29 & 0.14 & $86 \%$ & 0.9345 \\
\hline 29 & 0.15 & $85 \%$ & 0.9367 \\
\hline 29 & 0.16 & $84 \%$ & 0.9388 \\
\hline 29 & 0.17 & $83 \%$ & 0.9407 \\
\hline 29 & 0.18 & $82 \%$ & 0.9426 \\
\hline 29 & 0.19 & $81 \%$ & 0.9443 \\
\hline 29 & 0.20 & $80 \%$ & 0.9460 \\
\hline 29 & 0.21 & $79 \%$ & 0.9476 \\
\hline 29 & 0.22 & $78 \%$ & 0.9491 \\
\hline 29 & 0.23 & $77 \%$ & 0.9506 \\
\hline 29 & 0.24 & $76 \%$ & 0.9520 \\
\hline 29 & 0.25 & $75 \%$ & 0.9533 \\
\hline 29 & 0.26 & $74 \%$ & 0.9546 \\
\hline 29 & 0.27 & $73 \%$ & 0.9559 \\
\hline 29 & 0.28 & $72 \%$ & 0.9571 \\
\hline 29 & 0.29 & $71 \%$ & 0.9582 \\
\hline 29 & 0.30 & $70 \%$ & 0.9593 \\
\hline 29 & 0.31 & $69 \%$ & 0.9604 \\
\hline 29 & 0.32 & $68 \%$ & 0.9615 \\
\hline 29 & 0.33 & $67 \%$ & 0.9625 \\
\hline 29 & 0.34 & $66 \%$ & 0.9635 \\
\hline 29 & 0.35 & $65 \%$ & 0.9644 \\
\hline 29 & 0.36 & $64 \%$ & 0.9654 \\
\hline 29 & 0.37 & $63 \%$ & 0.9663 \\
\hline 29 & 0.38 & $62 \%$ & 0.9672 \\
\hline 29 & 0.39 & $61 \%$ & 0.9681 \\
\hline 29 & 0.40 & $60 \%$ & 0.9689 \\
\hline 29 & 0.41 & $59 \%$ & 0.9697 \\
\hline 29 & 0.42 & $58 \%$ & 0.9705 \\
\hline 29 & 0.43 & $57 \%$ & 0.9713 \\
\hline 29 & 0.44 & $56 \%$ & 0.9721 \\
\hline 29 & 0.45 & $55 \%$ & 0.9728 \\
\hline 29 & 0.46 & $54 \%$ & 0.9736 \\
\hline 29 & 0.47 & $53 \%$ & 0.9743 \\
\hline 29 & 0.48 & $52 \%$ & 0.9750 \\
\hline 29 & 0.49 & $51 \%$ & 0.9757 \\
\hline 29 & 0.50 & $50 \%$ & 0.9764 \\
\hline 29 & 0.51 & $49 \%$ & 0.9770 \\
\hline 29 & 0.52 & $48 \%$ & 0.9777 \\
\hline 29 & 0.53 & $47 \%$ & 0.9783 \\
\hline 29 & 0.54 & $46 \%$ & 0.9790 \\
\hline 29 & 0.55 & $45 \%$ & 0.9796 \\
\hline 29 & 0.56 & $44 \%$ & 0.9802 \\
\hline
\end{tabular}

The second, mathematically-equivalent, nonparametric approach considered in this investigation is that presented in [4]. For this approach the material from LANL was considered as being produced by a process, and it is the probability, $\mathrm{p}$, of that process producing an unacceptable output, where an unacceptable output is one whose concentration for an impurity exceeds the maximum limit for that impurity, that was investigated. For the LANL material to be successfully processed through MOX the value of $\mathrm{p}$ for a given impurity must be less than $2 \%$. This would lead to $98 \%$ of the LANL material having concentrations for the given impurity below the maximum limit for that impurity. As already noted above, all of the impurity measurements available for the LANL material were 
acceptable. So, with 29 acceptable outcomes for each impurity in a random sample of 29 items what upper confidence limit on the value of $\mathrm{p}$ can be determined utilizing the approach presented in [4]? For this approach, an upper $(1-\alpha) \times 100 \%$ confidence limit on the value of $p, p_{u}$, based upon a random sample of $\mathrm{n}=29$ items with $\mathrm{d}=0$ unacceptable items is given by

$$
\mathrm{p}_{\mathrm{u}}=\left(\mathrm{m}_{1} \mathrm{~F}_{\mathrm{m}_{1}, \mathrm{~m}_{2}, \alpha} / \mathrm{m}_{2}\right) /\left(1+\left(\mathrm{m}_{1} \mathrm{~F}_{\mathrm{m}_{1}, \mathrm{~m}_{2}, \alpha} / \mathrm{m}_{2}\right)\right)
$$

where $\mathrm{m}_{1}=2(\mathrm{~d}+1)=2, \mathrm{~m}_{2}=2(\mathrm{n}-\mathrm{d})=2(29)=58$, and $\mathrm{F}_{\mathrm{m}_{1}, \mathrm{~m}_{2}, \alpha}$ is the upper $\alpha$-tail of the $\mathrm{F}$ distribution with $\mathrm{m}_{1}$ and $\mathrm{m}_{2}$ degrees of freedom for the numerator and denominator, respectively.

Table 3 presents the confidence limits associated with various values for $\mathrm{p}_{\mathrm{u}}$. And from these entries, it is apparent that the results from this nonparametric approach are mathematically equivalent to the results presented in Table 2 for the earlier nonparametric approach. For example, from the shaded row in this table, there is $90 \%$ confidence that the probability of an unacceptable item from the sampled process is bounded by $7.63 \%$ and from Table 2 there is $90 \%$ confidence that $92.37 \%$ of the population is less that the largest measurement (an acceptable measurement) seen in the random sample of 29 items. 
Table 3. Confidence Intervals for Unacceptable Proportion using a Non-Parametric Approach

\begin{tabular}{|c|c|c|c|c|c|c|}
\hline \multicolumn{7}{|c|}{ Binomial-Based Approach with All Good in Random Sample } \\
\hline & & & & & & Upper Confidence \\
\hline & & & & & & Limit, $\mathrm{p}_{\mathrm{U}}$, for $\mathrm{p}$, where \\
\hline & \# bad & & & & & $\mathrm{p}=$ Prob(unacceptable item)) \\
\hline $\mathrm{n}$ & $\mathrm{d}$ & $\mathrm{m}_{1}$ & $\mathrm{~m}_{2}$ & Confidence $(1-\alpha) 100 \%$ & $\mathrm{~F}$ & $\operatorname{Prob}\left(p \geq p_{U}\right) \leq \alpha$, where $p_{U}=$ \\
\hline 29 & 0 & 2 & 58 & $50 \%$ & 0.701 & 0.0236 \\
\hline 29 & 0 & 2 & 58 & $51 \%$ & 0.722 & 0.0243 \\
\hline 29 & 0 & 2 & 58 & $52 \%$ & 0.743 & 0.0250 \\
\hline 29 & 0 & 2 & 58 & $53 \%$ & 0.765 & 0.0257 \\
\hline 29 & 0 & 2 & 58 & $54 \%$ & 0.787 & 0.0264 \\
\hline 29 & 0 & 2 & 58 & $55 \%$ & 0.810 & 0.0272 \\
\hline 29 & 0 & 2 & 58 & $56 \%$ & 0.833 & 0.0279 \\
\hline 29 & 0 & 2 & 58 & $57 \%$ & 0.856 & 0.0287 \\
\hline 29 & 0 & 2 & 58 & $58 \%$ & 0.881 & 0.0295 \\
\hline 29 & 0 & 2 & 58 & $59 \%$ & 0.905 & 0.0303 \\
\hline 29 & 0 & 2 & 58 & $60 \%$ & 0.931 & 0.0311 \\
\hline 29 & 0 & 2 & 58 & $61 \%$ & 0.957 & 0.0319 \\
\hline 29 & 0 & 2 & 58 & $62 \%$ & 0.984 & 0.0328 \\
\hline 29 & 0 & 2 & 58 & $63 \%$ & 1.011 & 0.0337 \\
\hline 29 & 0 & 2 & 58 & $64 \%$ & 1.040 & 0.0346 \\
\hline 29 & 0 & 2 & 58 & $65 \%$ & 1.069 & 0.0356 \\
\hline 29 & 0 & 2 & 58 & $66 \%$ & 1.099 & 0.0365 \\
\hline 29 & 0 & 2 & 58 & $67 \%$ & 1.130 & 0.0375 \\
\hline 29 & 0 & 2 & 58 & $68 \%$ & 1.162 & 0.0385 \\
\hline 29 & 0 & 2 & 58 & $69 \%$ & 1.195 & 0.0396 \\
\hline 29 & 0 & 2 & 58 & $70 \%$ & 1.229 & 0.0407 \\
\hline 29 & 0 & 2 & 58 & $71 \%$ & 1.265 & 0.0418 \\
\hline 29 & 0 & 2 & 58 & $72 \%$ & 1.301 & 0.0429 \\
\hline 29 & 0 & 2 & 58 & $73 \%$ & 1.339 & 0.0441 \\
\hline 29 & 0 & 2 & 58 & $74 \%$ & 1.379 & 0.0454 \\
\hline 29 & 0 & 2 & 58 & $75 \%$ & 1.420 & 0.0467 \\
\hline 29 & 0 & 2 & 58 & $76 \%$ & 1.463 & 0.0480 \\
\hline 29 & 0 & 2 & 58 & $77 \%$ & 1.508 & 0.0494 \\
\hline 29 & 0 & 2 & 58 & $78 \%$ & 1.554 & 0.0509 \\
\hline 29 & 0 & 2 & 58 & $79 \%$ & 1.603 & 0.0524 \\
\hline 29 & 0 & 2 & 58 & $80 \%$ & 1.655 & 0.0540 \\
\hline 29 & 0 & 2 & 58 & $81 \%$ & 1.709 & 0.0557 \\
\hline 29 & 0 & 2 & 58 & $82 \%$ & 1.767 & 0.0574 \\
\hline 29 & 0 & 2 & 58 & $83 \%$ & 1.827 & 0.0593 \\
\hline 29 & 0 & 2 & 58 & $84 \%$ & 1.892 & 0.0612 \\
\hline 29 & 0 & 2 & 58 & $85 \%$ & 1.961 & 0.0633 \\
\hline 29 & 0 & 2 & 58 & $86 \%$ & 2.034 & 0.0655 \\
\hline 29 & 0 & 2 & 58 & $87 \%$ & 2.114 & 0.0679 \\
\hline 29 & 0 & 2 & 58 & $88 \%$ & 2.200 & 0.0705 \\
\hline 29 & 0 & 2 & 58 & $89 \%$ & 2.293 & 0.0733 \\
\hline 29 & 0 & 2 & 58 & $90 \%$ & 2.396 & 0.0763 \\
\hline 29 & 0 & 2 & 58 & $91 \%$ & 2.511 & 0.0797 \\
\hline 29 & 0 & 2 & 58 & $92 \%$ & 2.639 & 0.0834 \\
\hline 29 & 0 & 2 & 58 & $93 \%$ & 2.785 & 0.0876 \\
\hline 29 & 0 & 2 & 58 & $94 \%$ & 2.954 & 0.0925 \\
\hline 29 & 0 & 2 & 58 & $95 \%$ & 3.156 & 0.0981 \\
\hline 29 & 0 & 2 & 58 & $96 \%$ & 3.404 & 0.1051 \\
\hline 29 & 0 & 2 & 58 & $97 \%$ & 3.727 & 0.1139 \\
\hline 29 & 0 & 2 & 58 & $98 \%$ & 4.188 & 0.1262 \\
\hline 29 & 0 & 2 & 58 & $99 \%$ & 4.991 & 0.1468 \\
\hline
\end{tabular}

\subsection{Parametric Approach}

Since there were so little data above the detection limits for $\mathrm{S}, \mathrm{F}$, and $\mathrm{Cl}$, only a nonparametric approach was used, and as seen in the previous discussion, while there was no immediate concern for the LANL material being suitable for processing through MOX regarding the concentrations for these three elements, there was too little data available to lead to useful confidence statements about the quantiles of interest for these three elements. 
For the other elements of this study, C, P, and N, there were more measurements recorded as being above the detection limits of the analytical process, and a parametric approach was used to investigate the quantiles of their population of concentration values. The use of a parametric approach relies on employing a probability distribution to represent that population.

\subsubsection{Elements with All Measurements above their Detection Limits}

For those impurities whose measured values were all above detection (i.e., C and P), JMP and its Goodness of Fit test was used to identify candidate probability distributions. First consider the JMP results for $\mathrm{P}$ that are provided in Exhibit 1. These results were generated using JMP's Descriptive Statistics platform and include a histogram and summary statistics for the $\mathrm{P}$ measurements. The leftside of this exhibit provides these results for the measurements as presented in Table 1, while the right-side of the exhibit provides JMP results for the natural logarithm of the measurements. A normal probability distribution was fit to both sets of data. Thus, while the left-side of the exhibit considered the use of a normal probability to represent the population of $\mathrm{P}$ measurements of the LANL material, the right-side explored the use of the lognormal distribution for this population. For each side of the exhibit, the results for a Shapiro-Wilk goodness of fit test for the normal probability are presented. If the $\mathrm{p}$-value for this test is less than 0.05 , the null hypothesis of normality is rejected at a $5 \%$ significance level. The p-value for the left-side is 0.0002 , and the p-value for the right-side is 0.0213. Thus, the hypothesis of the P measurements of Table 1 following a normal distribution was rejected at the $5 \%$ significance level and the hypothesis of a natural logarithm of the measurements following a normal distribution (or the original measurements following a lognormal distribution) was rejected at the 5\% significance level. Thus, no discernible distribution was discovered for the $\mathrm{P}$ measurements, which leads to a reliance on the nonparametric results from Tables 2 and 3 for an interpretation on the bound for the population of $\mathrm{P}$ measurements that is provided by the largest value in the sample, $130 \mu \mathrm{g} \mathrm{P} / \mathrm{g} \mathrm{Pu}$. 


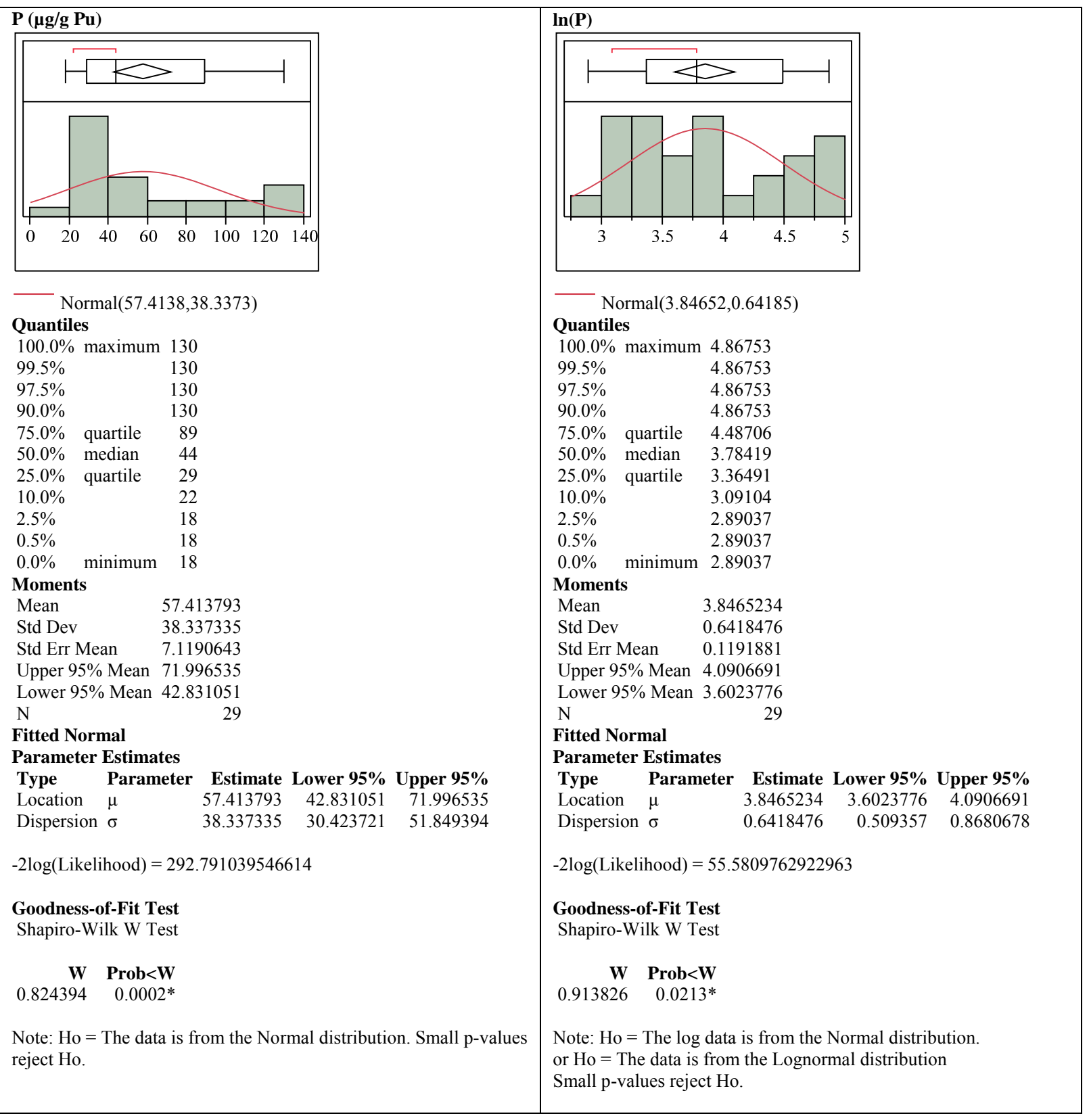

Exhibit 1. JMP Results for Candidate Probability Distributions for P Concentrations

Next consider similar results from JMP for the $\mathrm{C}$ data given in Exhibit 2. The left-side of this exhibit considered the use of a normal probability to represent this population while the right-side explored the use of the lognormal distribution (i.e., by fitting a normal probability distribution to the natural logarithm of the measured C values). The p-value of the Shapiro-Wilk test for the measurements was 0.0080 which leads to the rejection of the hypothesis that these measurements follow a normal probability distribution. The p-value for the natural logarithm of the measurements was 0.9981 , which is greater than 0.05 , and thus, the lognormal distribution was considered as a candidate distribution for the $\mathrm{C}$ measurements. 


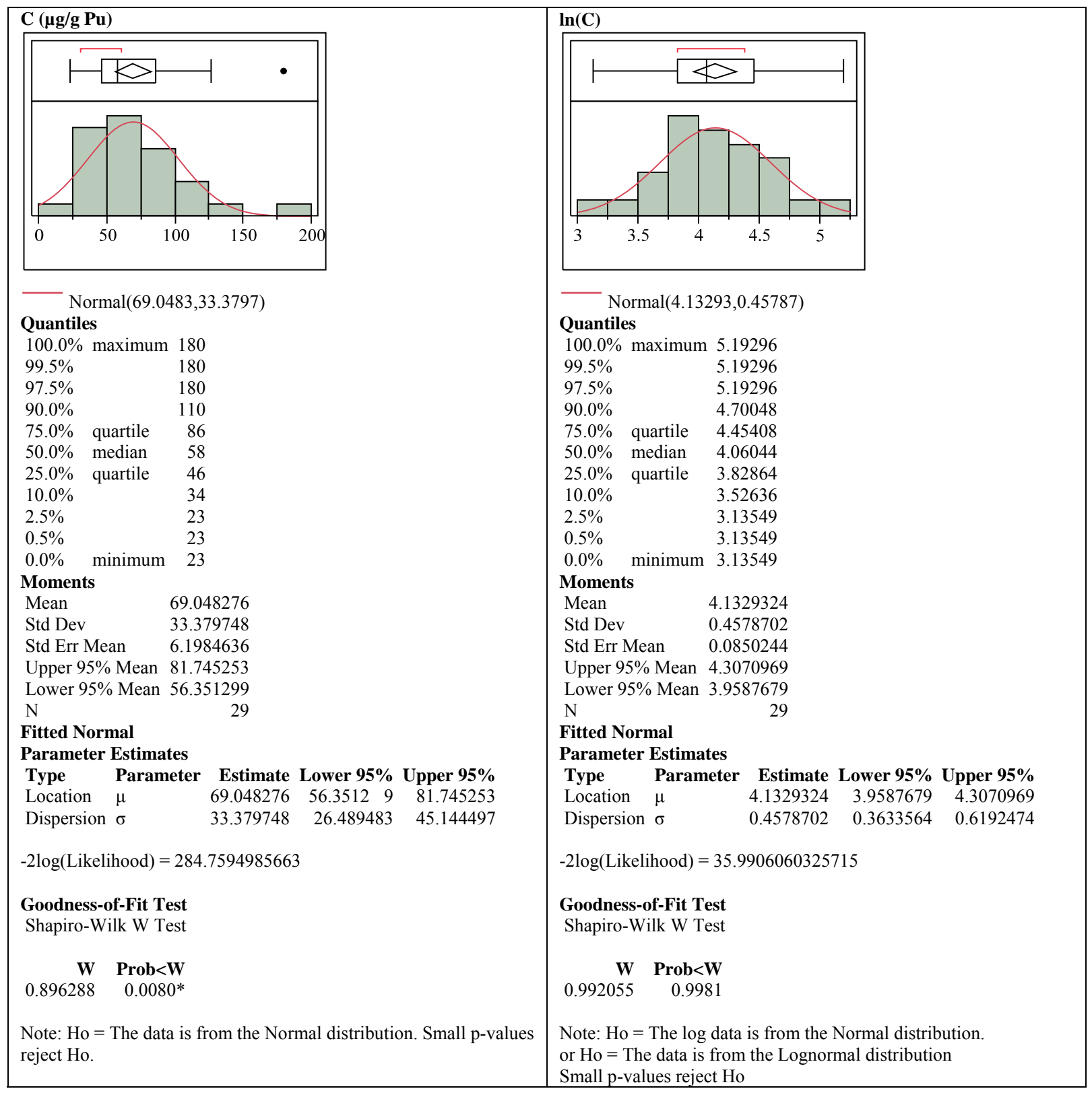

Exhibit 2. JMP Results for Candidate Probability Distributions for C Concentrations

Once a candidate probability distribution was identified, it was used to bound quantiles of the distribution with the desired confidence. Specifically, from [3], if a population is normally distributed with unknown mean and variance and if a random sample of $n$ observations from this distribution is taken, then the sample mean, $\bar{x}$, and the sample variance, $\mathrm{s}^{2}$, may be computed and used to determine an upper $100(1-\alpha) \%$ tolerance bound for the distribution of values with $100(1-\gamma) \%$ confidence as follows:

$$
\overline{\mathrm{x}}+\mathrm{k} \cdot \mathrm{s}
$$

where the equation for $\mathrm{k}$ involves the noncentral Student $\mathrm{t}$ distribution and is given by: 


$$
\mathrm{k}=\frac{\mathrm{t}\left(\gamma, \mathrm{n}-1, \sqrt{\mathrm{n}} \cdot \mathrm{z}_{1-\alpha}\right)}{\sqrt{\mathrm{n}}}
$$

where $t(\cdot)$ represents the upper- $\gamma$ tail of the noncentral Student $t$ distribution with $n-1$ degrees of freedom and noncentrality parameter given by $\sqrt{\mathrm{n}} \cdot \mathrm{z}_{1-\alpha}$, where $\mathrm{z}_{1-\alpha}$ is the $(1-\alpha) 100 \%$-tile of the standard normal distribution. The noncentral Student $t$ values were computed using JMP and were used to prepare Table 4, which provides an Upper Tolerance Limit (UTL) for 98\% of the each of the populations considered in this section with $95 \%$ confidence. For the natural logarithm, ln, values of for the C measurements, the sample mean, sample standard, and UTL were computed for the log values, and then the UTL results were converted back to the original units of $\mu \mathrm{g} / \mathrm{g} \mathrm{Pu}$ by exponentiation. The last column of Table 4 provides the maximum limit for $\mathrm{C}$. Thus, the results for $\mathrm{C}$ indicated no issue in the LANL material meeting the maximum limit for this element assuming that the measurements for this element follow a lognormal distribution.

Table 4. Upper Tolerance Limits for the $98^{\text {th }}$ Percentiles for Specified Probability Distributions

\begin{tabular}{|c|c|c|c|c|c|c|c|c|}
\hline Impurity & $\mathbf{n}$ & average & $\begin{array}{c}\text { standard } \\
\text { deviation }\end{array}$ & confidence & coverage & $\mathbf{k}$ & $\begin{array}{c}\text { UTL } \\
(\boldsymbol{\mu g} / \mathbf{g} \text { Pu) }\end{array}$ & $\begin{array}{c}\text { Maximum } \\
\mathbf{L i m i t} \\
(\boldsymbol{\mu g} / \mathbf{g} \text { Pu) }\end{array}$ \\
\hline $\ln (\mathrm{C})$ & 29 & 4.13293 & 0.45787 & 0.95 & 0.98 & 2.73947 & 219 & 500 \\
\hline
\end{tabular}

The $99.9^{\text {th }}$ quantile is the exceptional limit; it is a value in the very upper-tail of the population; and as such, it is very sensitive to the assumption of the probability distribution used to represent the concentration values. With that caution understood, Table 5 provides an estimate expressed in $\mu \mathrm{g} / \mathrm{g} \mathrm{P}$ for the $99.9^{\text {th }}$ quantile of the $\mathrm{C}$ distribution. The last column of Table 5 provides the exceptional limit for $\mathrm{C}$. The results from this table indicate no issue regarding the LANL material satisfying the exceptional limits for $\mathrm{C}$ if the $\mathrm{C}$ measurements follow a lognormal.

\section{Table 5. Upper Tolerance Limits for the $99.9^{\text {th }}$ Quantiles for Specified Probability Distributions}

\begin{tabular}{|c|c|c|c|c|c|c|c|c|}
\hline Impurity & $\mathbf{n}$ & average & $\begin{array}{c}\text { standard } \\
\text { deviation }\end{array}$ & confidence & coverage & $\mathbf{k}$ & $\begin{array}{c}\mathbf{U T L} \\
(\boldsymbol{\mu g} / \mathbf{g} \text { Pu) }\end{array}$ & $\begin{array}{c}\text { Exceptional } \\
\mathbf{L i m i t} \\
(\boldsymbol{\mu g} / \mathbf{g} \text { Pu) }\end{array}$ \\
\hline $\ln (\mathrm{C})$ & 29 & 4.13293 & 0.45787 & 0.95 & 0.999 & 4.04318 & 397 & 1500 \\
\hline
\end{tabular}

\subsubsection{Elements with Measurements above and below their Detection Limits}

As noted above, the sample results for $\mathrm{N}$ indicated no issue in the LANL material meeting the maximum and exceptional limits for MOX. It was also noted that for the nonparametic approach applied to the $\mathrm{N}$ measurements there was too little data available to lead to confident statements about the quantiles of interest for $\mathrm{N}$. However, since there are 12 below detect values for $\mathrm{N}$ recorded in the measurements of Table 1, the JMP software could not be used to support a parametric analysis. One of the features of the ProUCL software package is that it handles data sets containing below detection results. Exhibit 3 provides the results from fitting a normal and a lognormal distribution to the $\mathrm{N}$ measurement data (which contains 12 below detection values) using ProUCL. The Shapiro-Wilk was 
used to test for normality and for lognormality, and the p-values for both of these tests indicated that the hypotheses of normality and of lognormality are both rejected at the $5 \%$ significance level. Thus, neither of these proposed distributions is suitable for modeling the population of $\mathrm{N}$ concentration measurements. So, as in the case for $\mathrm{P}$ above, no discernible distribution was discovered for the $\mathrm{N}$ measurements, which leads to a reliance on the nonparametric results from Tables 2 and 3 for an interpretation on the bound for the population of $\mathrm{N}$ measurements that is provided by the largest value in the sample, $390 \mu \mathrm{g} \mathrm{N} / \mathrm{g} \mathrm{Pu}$.

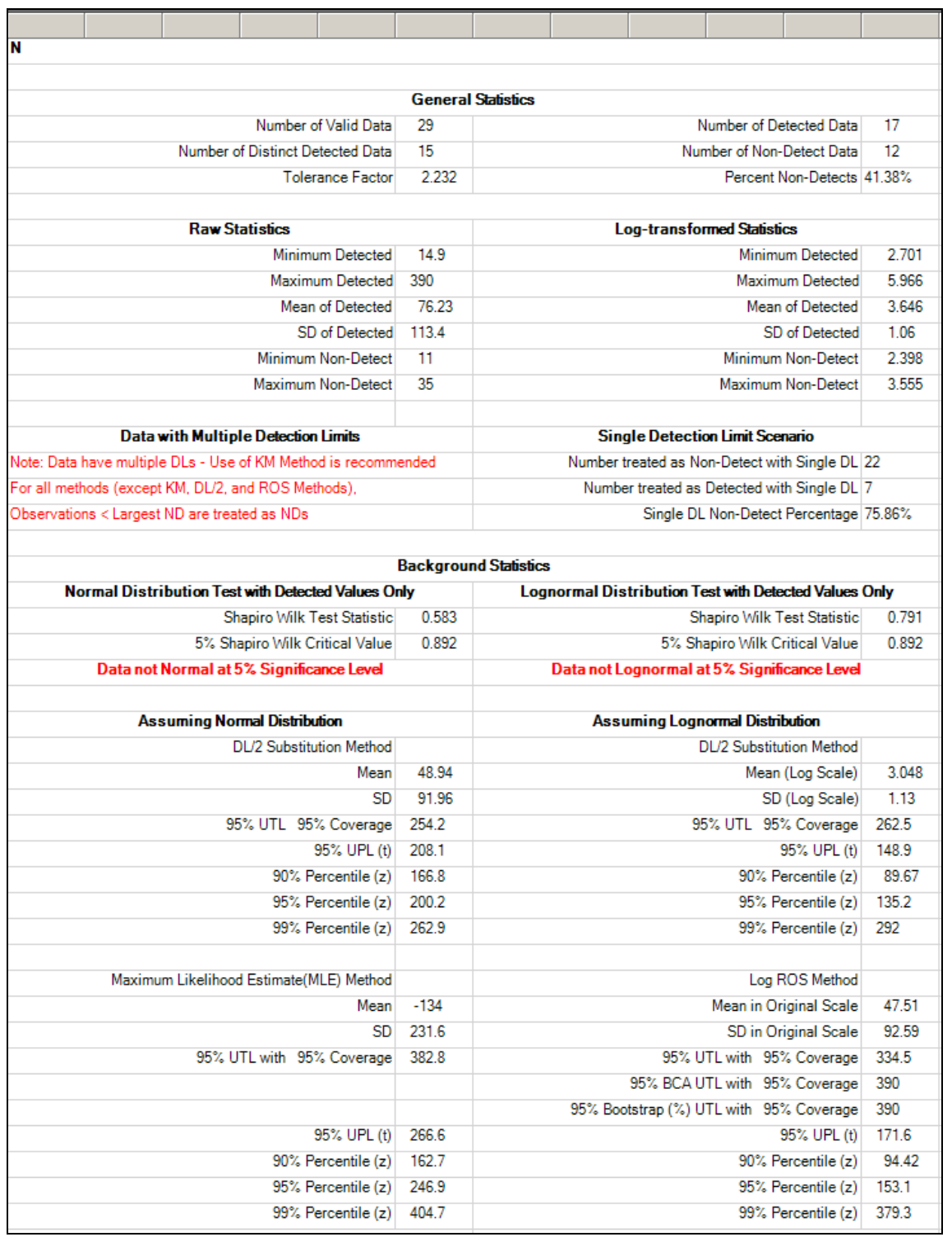

Exhibit 3. ProUCL Results for $\mathbf{N}$ 


\subsection{SUMMARY AND CONCLUSIONS}

The measurements evaluated as part of this study included LANL blend lots 1 through 29 and cover C, $\mathrm{Cl}, \mathrm{F}, \mathrm{N}, \mathrm{P}$, and $\mathrm{S}$. The LANL material is being considered for processing through MOX at SRS. There are specification limits for impurities in the feed to the MOX facility: a maximum limit and an exceptional limit. All of the sample measurements were below these limits, so there was no immediate concern regarding the LANL material being suitable for processing through MOX. A nonparametric approach was used to investigate the population of impurity levels of the LANL material. While the results from this approach did not indicate any problems for any of the impurities, there was too little data available to lead to useful confidence statements about satisfying the maximum and exceptional limits. Impurity data from additional random samples of the LANL material would be needed to increase the confidence level associated with the results from a nonparametric approach for investigating the population quantiles of interest.

For S, F, and Cl, only a nonparametric approach was used. A second approach, a parametric approach, was attempted for $\mathrm{C}, \mathrm{P}$, and $\mathrm{N}$. However, the results for the $\mathrm{P}$ and $\mathrm{N}$ measurements indicated that each of their respective populations was not well modeled by a normal or by a lognormal distribution. Thus, the conclusions for the $\mathrm{P}$ and $\mathrm{N}$ populations were those provided by the nonparametric approach. From the parametric approach, the results for C indicated no issue in the LANL material meeting the maximum limit for this element assuming that the measurements for this element follow a lognormal distribution.

\subsection{REFERENCES}

[1] JMP Version 9.0.0, SAS Institute, Inc., Cary NC, 2010.

[2] Singh, A, R Maichle, and N Armbya, "ProUCL Version 4.1 User Guide (Draft): Statistical Software for Data Sets with and without Nondetect Observations," EPA/600/R-07/041, US EPA, Office of Research and Development, Washington DC, May 2010.

[3] Krishnamoorthy, K and T Mathew, Statistical Tolerance Regions: Theory, Applications, and Computation, John Wiley \& Sons, Inc., Hoboken, New Jersey, 2009.

[4] Satterthwaite, FE, "Binomial and Poisson Confidence Limits," Industrial Quality Control, Volume 13, Number 11, pp 56-59, May, 1957. 
SRNL-STI-2012-00388

Revision 0

This page intentionally left blank. 


\section{Distribution:}

\begin{tabular}{|l|l|}
\hline \multicolumn{1}{|l|}{ Name: } & Location: \\
\hline J.S. Allender & $703-\mathrm{H}$ \\
\hline T.B. Edwards & $999-\mathrm{W}$ \\
\hline \hline P.L. Lee & $703-41 \mathrm{~A}$ \\
\hline E. N. Moore & $707-24 \mathrm{~B}$ \\
\hline M.G. Schwenker & $706-8 \mathrm{~F}$ \\
\hline \hline E.P. Shine & $703-41 \mathrm{~A}$ \\
\hline
\end{tabular}

